\title{
AS TRANSFORMAÇÕES PRODUTIVAS NA PÓS-GRADUAÇÃO: O PRAZER NO TRABALHO DOCENTE ESTÁ SUSPENSO?
}

\author{
The Productive Transformations in the Postgraduate: The Pleasure in the Teaching Work \\ Auspended?
}

\author{
Las Transformaciones Productivas en el Post-grado: ¿Está en Suspensión el Placer en el \\ Trabajo Socente?
}

\section{Les Transformations Productives au Troisième Cycle: Le Plaisir dans L'activité D'enseignement est-il Suspendu?}

Fábio Machado Ruza

Mestre em Educação pela Universidade do Estado de Minas Gerais (UEMG) e doutorando em Educação pela Universidade Federal de São Carlos (UFSCAR)

Eduardo Pinto e Silva

Doutor em Educação pela Universidade Estadual de Campinas (UNICAMP) e professor do Programa de Pós-Graduação em Educação da Universidade Federal de São Carlos (UFSCAR)

Recebido em: 16/10/2015 / Revisado em: 26/01/2016 / Aceito em: 23/03/2016

Resumo

O trabalho e a subjetividade do professor de pós-graduação se inscrevem em determinado contexto político-econômico configurado pela mundialização do capital, pela reforma do Estado e pela naturalização de formas de gestão e organização do trabalho orientadas pelos paradigmas objetivista, funcionalista e utilitarista. Nesse cenário, efetuam-se profundas reformas no papel desenvolvido pela universidade, que tende a se transformar em uma instituição gerencial, produtivista e mercantilizada. O docente vive, então, uma série de conflitos entre as exigências institucionais e sua subjetividade. Frente a isso, questionamos: o prazer no trabalho estaria colocado em suspenso? O sofrimento no trabalho encontraria possibilidades de, pela mediação do reconhecimento, se transmutar em prazer? A fim de examinarmos essa questão, foram levantados e analisados dados e documentos institucionais de uma universidade pública, a UNESP, e também aplicado um questionário a professores de dois programas de pós-graduação de elevada performance acadêmica. O aporte teórico pautou-se nas contribuições da psicodinâmica e da psicossociologia do trabalho. Apontamos que o prazer-sofrimento são elementos imbricados e que coexistem em todas as dimensões do trabalho do professor, ainda que determinadas atividades e relações gerem potencialmente maior prazer, e outras, maior sofrimento. A intensificação do trabalho, o desgaste frente às exigências de rotinização das tarefas e o significativo número de referências ao estresse e/ou adoecimento foram evidenciados. Mas há aspectos que ora se contrapõem, ora ofuscam esses indicadores de sofrimento. Conclui-se que, nesse jogo intrincado do par antitético prazer-sofrimento, ficam abertas várias possibilidades para as subjetividades docentes, que se situam entre o sofrimento patogênico e o sofrimento criativo.

Palavras-chave: educação superior; professor universitário; trabalho e subjetividade; sofrimento e prazer no trabalho; psicodinâmica e psicossociologia do trabalho.

\section{Abstract}

The work and subjectivity of the postgraduate professor are part of a certain political-economic context shaped by the globalization of capital, state reform and naturalization of forms of management and work organization guided by the objectivist, functionalist and utilitarian paradigms. In this scenario, profound reforms are carried out in the role developed by the university, which tends to become a 
managerial, productivist and commodified institution. The teacher lives, then, a series of conflicts between the institutional demands and their subjectivity. Faced with this, we asked: Would pleasure at work be put on hold? Would suffering at work find possibilities, through the mediation of recognition, to transmute into pleasure? In order to examine this question, data and institutional documents of a public university, the UNESP, were collected and analyzed, and a questionnaire was administered to professors from two postgraduate programs of high academic performance. The theoretical contribution was based on the contributions of Psychodynamics and Psychosociology of Work. We point out that pleasure-suffering are imbricated elements that coexist in all dimensions of the professor work, although certain activities and relationships potentially generate greater pleasure and, at the same time, greater suffering. The intensification of the work, the wear and tear in front of the demands of routine tasks and the significant number of references to stress and / or illness were evidenced. But there are aspects that sometimes contradict each other, sometimes overshadowing these indicators of suffering. It is concluded that, in this intricate game of the antithetical pair pleasure-suffering, several possibilities open to the teaching subjectivities that are situated between the pathogenic suffering and the creative suffering.

Keywords: college education; college professor; Work and subjectivity; Suffering and pleasure at work; Psychodynamics and work psycho-sociology.

\section{Resumen}

El trabajo y la subjetividad del profesor del post-grado están inscritos en determinado contexto politico-económico configurado por la mundialización del capital, reforma del Estado y naturalización de formas de gestión y organización del trabajo orientadas por los paradigmas objetivista, funcionalista y utilitarista. En esta escena, son efectuadas profundas reformas en la función ejercida por la universidad, que tiende a transformarse en una institución gerencial, productivista y mercantilizada. El docente vive, entonces, una serie de conflictos entre las exigencias institucionales y su subjetividad. Ante esto, cuestionamos: ¿estaría en suspensión el placer en el trabajo? ¿El sufrimiento en el trabajo encontraría posibilidades de, por el reconocimiento, transformarse en placer? Con el fin de examinar esta cuestión, fueron levantados y analizados datos y documentos institucionales de una universidad pública, la UNESP, y realizada una encuesta con profesores de dos programas de post- grado de elevada performance académica. El aporte teórico está basado en las contribuciones de la Psico-dinámica y de la Psico-sociología del Trabajo. Apuntamos que el placer-sufrimiento son elementos interconectados y que coexisten en todas las dimensiones del trabajo del profesor, aunque determinadas actividades y relaciones causen, potencialmente, mayor placer y, otras, mayor sufrimiento. La intensificación del trabajo, el desgaste ante las exigencias de tareas de rutina y el significativo número de referencias al estrés y/o enfermarse fueron evidenciados. Pero hay aspectos que ora contraponen, ora ofuscan estos indicadores de sufrimiento. Se concluye que, en este juego intrincado del par antitético placer-sufrimiento, quedan abiertas varias posibilidades para las subjetividades docentes, que se ubican entre el sufrimiento patogénico y el sufrimiento creativo.

Palabras clave: Educación terciaria; Profesor universitario; Trabajo y subjetividad; Sufrimiento y placer en el trabajo; Psico-dinámica y psico-sociología del trabajo.

\section{Résumé}

Le travail et la subjectivité du professeur du troisième cycle s'inscrivant dans certain contexte politico-économique configurés par la mondialisation du capital, par la réforme de l'Etat et par la naturalisation des formes de gestion et de l'organisation du travail guidées par les paradigmes objectiviste, fonctionnaliste et utilitariste. Dans ce scénario, profondes réformes sont efféctues dans le papier développé par l'Université, qui tend à devenir une institution de gestion productiviste et dévalorisée. L'enseignant vit, alors, une série de conflits entre les exigences institutionnelles et sa subjectivité. Dans ce cas, on pose la question: le plaisir au travail est placé en attente? Est-ce que la souffrance au travail peut trouver des possibilités de se transmuter en plaisir à l'aide de la médiation de la reconnaissance? Afin d'examiner cette question, des documents et des données institutionnelles d'une université publique (UNESP) ont été recueillies et analysées, ainsi que des questionnaires ont été appliqués aux enseignants des deux programmes de troisième cycle de haute performance. La contribution théorique a été basée dans les contributions de la Psychodynamique et de la psychologie sociale du travail. Nous signalons que la plaisir-souffrance sont des éléments imbriqués et qui coexistent dans toutes les dimensions du travail de l'enseignant, bien que certaines activités et relations puissent générer plus de plaisir et, d'autres, plus de souffrance. L'intensification du travail, l'usure face aux exigences de la routine des tâches et l'important nombre de références au stress et/ou à la maladie ont été mis en évidence. Mais il y a des aspects qui parfois s'opposent et parfois éclipsent ces indicateurs de souffrance. En conclusion, dans ce jeu complexe du paire antithétique plaisir-souffrance, sont ouvertes plusieurs possibilités pour les subjectivités enseignantes qui se sont situées entre la souffrance pathogène et la souffrance créative.

Mots-clés: troisième cycle; professeur d'université; travail et subjectivité; la souffrance et le plaisir au travail; psychodynamique et 
psycho-sociologie du travail.

A pesquisa ${ }^{1}$ que subsidia a produção deste texto tem como objetivo analisar as relações entre o trabalho e a subjetividade do professor de pós-graduação da Universidade Estadual Paulista Júlio de Mesquita Filho (UNESP).

A universidade estatal pesquisada se caracteriza por passar por uma série de transformações produtivas nas práticas e relações universitárias. Ao delimitar nosso objeto de estudo, optamos por investigar dois programas de pós-graduação na área de Ciências Humanas, de elevada performance acadêmica, com base no pressuposto de que poderiam apresentar significativa conformação aos critérios do Sistema de Avaliação da Pós-Graduação empreendido pela Coordenação de Aperfeiçoamento de Pessoal de Nível Superior (CAPES).

No presente texto, apresentamos uma sistematização dos dados obtidos por meio de questionários e documentos, analisando-os à luz das contribuições teóricas da psicossociologia e psicodinâmica do trabalho. Para tanto, procuramos responder à questão de seu subtítulo: o prazer no trabalho estaria suspenso? Questão essa que se desdobra em outra: o sofrimento no trabalho encontraria possibilidade de, pela mediação do reconhecimento, se transmutar em prazer?

Tomamos como referência para compreensão da unidade contraditória sofrimento prazer uma série de definições conceituais da psicodinâmica do trabalho, que nos apontam para o sofrimento criativo, o sofrimento patogênico, assim como para o prazer no trabalho, sublimação e alguns conceitos correlatos, tais como: real do trabalho, reconhecimento, relações de trabalho, sentido do trabalho, subjetividade (intersubjetividade), solidariedade e ressonância simbólica, dentre outros (Dejours, 2011a, 2011b).

Não é nosso intuito, nem caberia neste artigo, uma exposição detalhada de cada um dos conceitos elencados. Não obstante, vale indicar que o prazer assume formas muito diferenciadas. No trabalho, as pulsões desejantes encontram saídas gratificantes e dessexualizadas que exigem renúncias e um forçoso processo de inscrição da subjetividade no coletivo e na vida institucional que não nos exime do sofrimento, ainda que este possa ser criativo. Prazer sublimatório e sofrimento criativo geralmente se possibilitam quando há solidariedade, cooperação e reconhecimento do/no trabalho pelos pares e gestão.

Em relação ao reconhecimento, destacamos que, na perspectiva da psicodinâmica do trabalho, ele assume importante papel na construção de sentido e na conversão do sofrimento em prazer no trabalho: "a construção do sentido do trabalho pelo reconhecimento - premiando o indivíduo quanto a suas expectativas com respeito à sua realização pessoal (edificação da identidade no campo social) - pode transformar o sofrimento em prazer" (Dejours, 2011a, p. 88). Mas tanto o prazer quanto o reconhecimento no trabalho podem encontrar entraves.

O prazer pode se aprisionar em sua forma agressiva, senão fetichizada, e cair nas armadilhas do que Freud denominou como uma situação para além do princípio do prazer (Freud, 1920/1996). Nesse caso, as condições sublimatórias, como a de reconhecimento, solidariedade-cooperação e autonomia são, de alguma forma, suplantadas por modelos de gestão avessos à autonomia ou marcadamente heterônomos.

A psicossociologia do trabalho mostra que o paradigma gerencial tem utilizado o reconhecimento como importante ferramenta de manipulação da subjetividade. Ao apresentar a organização como uma "máquina" de prazer e angústia, Aubert e Gaulejac (1991) apontam para a problemática de um pacto narcísico estabelecido entre o indivíduo e a instituição. Ao tornar o reconhecimento uma ferramenta de dominação, a organização tende a fraudar os desejos, valores e consciência de si do trabalhador. Induz este a cair numa armadilha da excelência, referida por Gaulejac (2007, p.173) como uma insana "corrida para o sempre mais". Pode-se considerar que se produz uma falsa impressão de obtenção de prazer.

No entanto, a forjada busca por prestígio, sucesso, etc., tende a constituir um prazer do tipo agressivo, e não raro conduz à perda de sentido e à naturalização de condições de trabalho intensas e adversas (Aubert \& Gaulejac, 1991; Gaulejac, 2007; Silva, 2013), as quais podem fortalecer o sofrimento patogênico em detrimento do sofrimento criativo (Dejours, 2011a). Dessa forma, podemos considerar a situação o que denominamos uma malversação da dinâmica do reconhecimento, que conduz o profissional ao vazio ontológico e ao sofrimento patogênico, por vezes transmutado em adoecimento.

Portanto, o par antitético prazer-sofrimento não pode ser compreendido de forma reducionista, como se fosse um par dicotômico ou um binômio, nem tampouco pode ser analisado como algo meramente da ordem individual, mas, outrossim, como uma contradição cujo interjogo dialético só se mobiliza na vida institucional e sob a influência de modelos de gestão. Como apontaremos, na atual configuração do mundo do trabalho e do modelo gerencialista, sob os auspícios das normativas de avaliação de desempenho e de produtividade, a heteronomia e a competitividade são fatores que ameaçam as possibilidades de um trabalho sublimatório e cooperativo (Dejours, 2008; Gaulejac, 2007), o que nos remete às questões explicitadas nesta introdução e subtítulo.

1 A pesquisa recebe financiamento da Fundação de Amparo à Pesquisa do Estado de São Paulo (FAPESP). 


\section{Método}

A pesquisa que subsidia a produção deste texto analisa o trabalho e a subjetividade do professor que atua em dois programas de pós-graduação da UNESP bem avaliados pela CAPES e que integram a área de Ciências Humanas. Na primeira etapa da pesquisa, procuramos compilar documentos e dados objetivos da instituição (publicações de anuários, regulamentos e dados estatísticos da instituição e dos programas selecionados), assim como artigos, dissertações e teses concernentes à UNESP em especial, e aos processos de expansão da educação superior no Brasil nas duas últimas décadas, de modo geral. Tal processo, como argumentaremos, ocorre, em linhas gerais, sob as diretrizes da reforma do Estado e da ideologia gerencialista.

Na segunda etapa da pesquisa, aplicamos um questionário com 26 questões, entre abertas e fechadas. Com as questões fechadas procuramos apreender o perfil dos participantes e os indicadores que apontam para o sofrimento e prazer no trabalho (Merlo \& Mendes, 2009). Nesse sentido, as questões versaram sobre o perfil do professor (sexo, faixa etária, estado civil, titulação acadêmica, tempo de serviço etc.), sua atuação profissional (atividades acadêmico-profissionais desenvolvidas, números de projetos de pesquisa, de produção acadêmica, de orientandos, de disciplinas ministradas etc.), sua rotina (horas semanais dedicadas ao trabalho, descrição das atividades desenvolvidas nos feriados e finais de semana etc.) e sua impressão a respeito de alguns assuntos, como: os modelos avaliativos da UNESP e da pós-graduação; o ambiente e as condições de trabalho; e as vivências de saúde e doença no trabalho. Por sua vez, a partir das questões abertas, procuramos aprofundar a compreensão das condições de trabalho, de seu ritmo e dos elementos de satisfação e insatisfação, de modo a termos subsídios para explorar a psicodinâmica do par sofrimento-prazer no trabalho.

Ao utilizarmos em nosso questionário a estratégia de indagar sobre distintas questões do cotidiano do trabalho do professor, optamos por evitar, propositalmente, o uso dos termos prazer e sofrimento, e adotamos os termos satisfação e insatisfação profissional, em decorrência de nos parecer ser mais facilmente apreendido pelos participantes da pesquisa. Por outro lado, satisfação e prazer no trabalho, embora sejam termos não redutíveis entre si, possuem pontos de convergência que, resguardadas suas diferenças epistemológicas, podem ser associados. No esforço de conceituá-los, Martinez e Paraguay (2003) concluem que:

A teoria de Locke sobre satisfação no trabalho e a psicodinâmica do trabalho de Dejours são duas teorias que contemplam as relações entre satisfação no trabalho e saúde, em que satisfação no trabalho está relacionada ao prazer ou à felicidade no trabalho e insatisfação está na origem do desprazer ou do sofrimento no trabalho. (p. 73)

Como os termos satisfação e insatisfação no trabalho são compreendidos mais facilmente pelas pessoas, os utilizamos no questionário para identificar os fatores que cooperavam para um estado emocional prazeroso e para um não prazeroso no trabalho. Vale explicitar, no entanto, que nossa compreensão sobre o prazer toma como referência a obra dejouriana (Dejours, 2011a, 2011b), a qual possui como uma de suas bases epistemológicas a psicanálise. Compreendemos que o prazer é ao mesmo tempo indissociado e irredutível ao sofrimento. Ao contrário do senso comum, que toma prazer e sofrimento como pares dicotômicos, senão excludentes, os compreendemos como polos de um par antitético ou, ainda, como uma unidade contraditória cujos polos se relacionam de forma dialética, conforme argumentamos na introdução deste texto.

O questionário foi entregue para cada um dos sujeitos da pesquisa por um dos pesquisadores, nas dependências da UNESP, no mês de novembro de 2013. Como possuía questões que exigiam elevado grau de reflexão, foi-lhes facultada a possibilidade de entregá-lo posteriormente. Entre os 60 professores dos programas pesquisados, 36 preencheram voluntariamente e individualmente o questionário, entregando-o ao pesquisador sem intermediações. Obtivemos uma taxa de participação de $60 \%$ do corpo docente examinado. No que tange aos dados objetivos do questionário, eles foram tratados pelo programa Statistical Package for the Social Sciences (SPSS), enquanto os dissertativos foram analisados à luz das contribuições teóricas da psicodinâmica e da psicossociologia do trabalho.

Por fim, em relação aos principais aspectos éticos que nortearam a investigação, primeiramente ressaltamos que a pesquisa foi aprovada pelo Comitê de Ética em Pesquisa com Seres Humanos da UFSCar. A participação dos professores sempre foi voluntária e acompanhada do preenchimento do "Termo de Consentimento Livre e Esclarecido" (TCLE). Além disso, garantimos o anonimato dos participantes e dos programas de pós-graduação analisados.

\section{As Transformações Produtivas na UNESP e a Intensificação do Trabalho do Professor sob as Diretrizes da Ideologia Gerencialista e da Quantofrenia}

A universidade brasileira se insere em uma conjuntura social configurada pela predominância da esfera financeira de 
acumulação capitalista, a era da mundialização do capital (Chesnais, 1996), e pela reforma do aparelho de Estado, pautada por diretrizes neoliberais (Paulani, 2008). Nesse cenário, profundas reformas no papel a ser desenvolvido pela universidade estão em curso, transformando-a em uma instituição "empresarial" e mercantilizada (Sguissardi \& Silva, 2009).

O Estado, com o objetivo estratégico de atrair fluxos de investimento financeiro, é alçado à condição de agente indutor de práticas de inovação tecnológica, promovendo a mercantilização do ensino superior, especialmente a partir da adoção de um modelo de ciência instrumental e de universidade pragmática que se volta aos interesses do capital financeiro-industrial (Sguissardi \& Silva, 2009). Tal transformação é conduzida no âmbito de uma administração gerencial já em voga no Brasil, desde o início da década de 1980, e que ganhou forma sistemática com a reforma do aparelho de Estado em 1995, ao estabelecer a necessidade de se reformular a administração das instituições públicas (business administration) a fim de conquistar suposta "eficiência" nesse setor. Discurso que foi amplamente proferido pelo governo de Fernando Henrique Cardoso (FHC). Como o ex-presidente afirmou em um seminário:

Nós temos que preparar a nossa administração para a superação dos modelos burocráticos do passado, de forma a incorporar técnicas gerenciais que introduzam na cultura do trabalho público as noções indispensáveis de qualidade, produtividade, resultados, responsabilidade dos funcionários, entre outras (Cardoso, 2007, p. 17).

A tendência de administrar as instituições públicas a partir de um modelo gerencial se faz presente a partir de mediações e contradições, especialmente ao instituir uma série de práticas de controle do trabalho e dos trabalhadores por meio da gestão por resultados (Gaulejac, 2007). A universidade vem sendo conduzida nesse âmbito gerencial desde então, especialmente a partir de duas frentes de atuação: a racionalização dos recursos humanos e a manipulação da subjetividade, com destaque aos mecanismos de avaliação do trabalho.

A primeira está na adoção de práticas que visam a "otimização" dos "recursos humanos" por meio de um modelo de expansão universitária em que há um descompasso entre o crescimento de matrículas, docentes e funcionários. Na UNESP, o crescimento no número de estudantes de graduação e pós-graduação, durante o período de 1992-2013, foi de 130,1\%, passando de 21.325 para 49.082 estudantes. Essa expansão, que contrasta tanto com a inexpressiva ampliação do corpo docente, de 6,8\% (ao sair de 3.492 professores, em 1992, e atingir 3.730, em 2013), quanto com a retração de 2,8\% no número de técnicos administrativos (ao diminuir de 7.462 profissionais, em 1992, para 7.247, em 2013). Como resultado, houve expressivo aumento da média de alunos (graduação e pós-graduação) por docente, que saiu de 6,11, em 1992, para 13,15, em 2013 (UNESP, 2004, 2014).

A dita "otimização" de "recursos humanos" expressa uma das facetas nefastas do paradigma gerencial na educação superior. E essa realidade tende a se agravar, pois, além da intensificação do trabalho, há em curso uma política de flexibilização das formas de contratação. Na UNESP, em 1992, predominava os contratos de tempo integral (3.225) através do "Regime de Dedicação Integral à Docência e à Pesquisa" (RDIDP), enquanto havia apenas 267 docentes em contratos de tempo parcial divididos entre o "Regime de Turno Completo" (RTC), com contrato de 24 horas semanais, e o "Regime de Turno Parcial" (RTP), com contrato de 12 horas semanais. Já em 2013, ainda que tenha se mantido o predomínio da contratação em RDIDP (3.133), o número de contratados com regime parcial (RTC e RTP) dobrou: 597 (UNESP, 2004, 2014). Ademais, a UNESP não divulgou nos Anuários Estatísticos o total de docentes temporários, condição que de antemão, interpretamos como forma de mascarar a realidade institucional da precarização das condições de trabalho na universidade.

A busca em atingir suposta eficiência e eficácia no funcionamento da universidade mediante "racionalização" dos recursos contribui para que o docente intensifique suas demandas profissionais: maior quantidade de alunos por sala de aula, de aulas ministradas, de orientandos de trabalho de conclusão de curso, entre outras atividades. Na pós-graduação, como veremos, a carga de trabalho se eleva ainda mais em decorrência da pressão na produção de artigos científicos e da necessidade de atuar numa multiplicidade de áreas: ensino, comissões e orientação na pós-graduação. Realidade apontada pela literatura como nociva à saúde, ao convívio social e ao trabalho docente (Bosi, 2007; Borsoi \& Pereira, 2013; Sguissardi \& Silva, 2009; Silva, 2015), aspectos que procuraremos evidenciar na análise dos questionários.

A segunda frente de atuação tem como característica fundamental o paradigma utilitarista e a constante busca em medir e apontar índices da atividade humana, inscrevendo-a numa matematização do real, de forma a produzir hierarquizações dos desempenhos de pessoas, grupos e instituições. Espécie de gestão como doença social, a quantofrenia ou doença da medida atua como elemento orientador por excelência dos modelos de administração gerencial, no qual se concebe o trabalhador "como agente a serviço da produção" (Gaulejac, 2007, p. 76). A busca por uma matematização do trabalho vivo em prol de suposta "eficiência e eficácia" tende a recair em vazio ontológico e insignificância (Gaulejac, 2007). E, como a dinâmica de funcionamento da universidade não se reduz à lógica empresarial, tal feito gera sérios prejuízos à prática universitária e ao bem-estar docente.

A doença da medida se espraia na instituição universitária brasileira, em grande medida, por intermédio do sistema CAPES (Comissão de Aperfeiçoamento de Pessoal do Nível Superior) de regulação da pós-graduação e das avaliações institucionais das universidades, em que se formulam e comparam índices de produtividade acadêmica com a finalidade de 
regular o trabalho e fomentar uma corrida por desempenho entre os atores e as instituições. Como as lógicas do mercado e do universo empresarial se imiscuem no funcionamento da universidade, tais índices de produtividade passam a ser considerados neutros e, por assim dizer, válidos para mensuração de suposta qualidade e para distribuição de recursos entre os docentes e as instituições (Sguissardi, 2010; Silva, 2013). Os professores, em sua maioria, alvos desta sedução institucional, passam a identificar e a naturalizar uma "cultura de excelência" (Mancebo, 2007; Silva, 2013, 2015) que tem no produtivismo acadêmico tanto seu baluarte quanto seu efeito colateral: "excessiva valorização da quantidade da produção científico-acadêmica, tendendo a desconsiderar sua qualidade" (Sguissardi, 2010, p.1) e relevância social.

O poder gerencial atua, deste modo, procurando "mobilizar" a fundo as estruturas conscientes e inconscientes do docente, mediante a oferta e retirada de um suposto "amor recompensador" por parte da organização:

Ela [organização] provoca por ela mesma um duplo movimento fundado no oferecimento de prazer (reconhecimento narcisista, prazer de dominação, sentimento de onipotência...) e na ameaça (medo de fracassar, controles generalizados, pressão de trabalho, tensões nervosas...). A organização suscita assim a formação de uma estrutura psicológica conflitante e fechada, onde o prazer agressivo, a busca de um ideal de perfeição, a procura de satisfação narcísica e a angústia de perder o amor da organização se reforçam reciprocamente. (Aubert \& Gaulejac, 1991, p. 245)

As adesões a tais valores instrumentais e produtivistas são fundadas e/ou forjadas na solicitação de um amor «recompensador» (desejo narcísico de reconhecimento, onipotência e sucesso) que se traduz em progressão de carreira, na conquista de financiamentos de pesquisa e na ascensão à hierarquia da estrutura acadêmica, visto que, no atual modelo de universidade, eles se constituem como "moedas de troca" no "mercado de bens científicos" (Bourdieu, 2004). Como dito acima, estão, ainda, baseados na possibilidade desse amor "recompensador" ser retirado (ausência de reconhecimento e receio de fracasso), traduzindo-se no descredenciamento da pós-graduação, na perda de financiamentos de pesquisa e no estigma de "incompetência profissional" formulado pelos pares (Aubert \& Gaulejac, 1991; Gaulejac, 2007). Especialmente na realidade da UNESP, essa "angústia" se agudiza pela possibilidade real do docente com regime integral (RDIDP) ser reconduzido para regimes de trabalho parciais (RTC e RTP) caso não atinja os critérios mínimos de desempenho profissional formulado pela Comissão Permanente de Avaliação (UNESP, 2007).

O professor da pós-graduação se defronta constantemente com a possibilidade de oferta e ameaça de retirada deste “amor" organizacional presente na instituição universitária. A universidade é apresentada, assim, como local de identificação, projeção e introjeção, efetivada pela via da satisfação de um narcisismo sedento por reconhecimento, prestígio e poder. A "mobilização" fomentada pelo ideal da organização não concede um prazer legítimo, mas suposto prazer decorrente da malversação do reconhecimento, situação que se apresenta nociva ao bem-estar físico e psicológico do professor. Tal prejuízo ocorre porque a dimensão prescritiva e a dominação organizacional simplificam a dinâmica do trabalho real: cooperação-retribuição, inteligência prática, liberdade, criatividade, subversão, etc., e induz o profissional a adentrar em uma rotina de trabalho árdua, competitiva e individualizada. Toda essa situação colabora para que a injunção organizacional atue no sentido de uma manipulação e/ou o "desaparecimento" dos desejos no trabalho e, consequentemente, gere uma crise de sentido profissional (Gaulejac, 2007; Dejours, 2011a; Silva, 2013, 2015).

Embora a procura em obter prazer e transformar o sofrimento pela mediação do reconhecimento seja passível de engodos, em nosso questionamento sobre a suspensão ou não do prazer no trabalho subjaz uma contra-hipótese: a de que subsistam potencialidades sublimatórias, especialmente entre os sujeitos conscientes das limitações e contradições da racionalidade produtiva. Potencialidades que possam vir a constituir estratégias que mantenham o equilíbrio psíquico e o sentido do trabalho.

\section{Sofrimento, Prazer e Adoecimento no Trabalho do Professor da Pós-graduação: Para Além da "Satisfação Profissional"}

Os docentes que responderam ao questionário, em sua maioria, são do sexo feminino $(69,4 \%)$ e possuem, pelo menos, um filho (72,2\%). Há um predomínio daqueles que possuem uma relação marital: $50 \%$ casados e 5,6\% com união estável, seguido por $19,4 \%$ de solteiros, $19,4 \%$ de separados e 5,6\% de viúvos. Além disso, existe uma boa distribuição entre os grupos etários: trinta anos (25\%), quarenta anos (16,7\%), cinquenta anos $(36,1 \%)$ e sessenta anos $(22,2 \%)$. Tais percentis apontam para certa renovação do quadro docente, realidade ratificada por haver certo predomínio de professores com menos de 10 anos de trabalho na UNESP $(41,7 \%)$ e por apenas 5,6\% estarem a mais de 30 anos na UNESP. Os demais grupos são bem distribuídos: entre 10 a 20 anos $(22,2 \%)$ e de 20 a 30 anos $(27,8 \%)$. Todavia, quando se refere às instituições onde cursaram a pós-graduação, verifica-se certa endogenia acadêmica, pois todos concluíram o mestrado em universidades 
paulistas: UNESP (33,3\%); USP (33,3\%); UNICAMP (16,7\%); UFSCar (5,6\%), sendo que 11,1\% fizeram doutorado direto. A mesma concentração ocorreu com o doutorado, pois $91,6 \%$ o fizeram no estado de São Paulo: UNESP (38,9\%); USP (38,9\%); UNICAMP (13,8\%), sendo que, apenas 2,8\% cursaram na PUC-Rio (2,8\%) e 5,6\% no exterior. Por fim, 94,4\% dos docentes são RDIDP e 5,6\% aposentados.

A satisfação profissional do professor da pós-graduação da UNESP está presente nas respostas do questionário, que, como apontamos e justificamos na introdução, incluiu propositalmente este termo, de forma a evitar o uso de "sofrimento" e "prazer". Ainda que a (suposta) "satisfação profissional" não seja plena e não abarque a totalidade do corpo docente, ela foi predominante nas respostas, e minoritária foi o seu contrário, a "insatisfação": 19,4\% consideram-se muito satisfeitos; a maioria $(52,8 \%)$ considera-se satisfeita; $25 \%$ se considera parcialmente satisfeito; e uma minoria $(2,8 \%)$ se diz insatisfeita profissionalmente. Tais percentis evidenciam que a maioria do corpo docente está, em tese, satisfeita no trabalho ou em sua atual situação profissional, ainda que com graus distintos.

Mas não se pode desconsiderar que, concomitantemente à satisfação, tem-se um contingente de respostas, ainda que pequeno, de insatisfação. Esta pode estabelecer, com a dita "satisfação", múltiplas relações contraditórias, senão ambivalentes, como no caso da referência ao prazer indissociado do estresse (vide transcrição logo abaixo). Isto é o que sugere outras respostas do questionário, como veremos mais adiante, sobretudo as questões relacionadas ao cotidiano de trabalho, à sobrecarga/intensificação do trabalho, ao reconhecimento, ao jogo político-institucional e às atividades profissionais. Mas continuemos na trilha da identificação do prazer no trabalho.

A dimensão "satisfação profissional", conforme apontam os professores, abarca a prática da pesquisa e da produção acadêmica, a orientação dos alunos e a docência. Vejamos alguns relatos:

Reconhecimento de minha produção, formação dos alunos e possibilidade de continuar pesquisando assuntos do meu interesse. (Questionário 36)

Vocação para o ensino, a orientação e a pesquisa. Na verdade, não se trata de uma profissão, mas de um modo de vida, pois a maior parte de minhas atividades diz respeito ao conhecimento, à sua produção e transmissão. Tudo feito com prazer. (Questionário 8)

O trabalho de orientação, tanto no nível de Graduação como de Pós-Graduação, é que me permite acompanhar de fato o crescimento acadêmico e pessoal dos alunos. As aulas, tanto prepará-las quanto ministrá-las; a pesquisa (sua elaboração, descobrir algo novo, encontrar soluções, discutir). (Questionário 12)

Apesar do estresse, ser docente, desenvolver pesquisa e ter acesso a leituras são, para mim, uma satisfação enorme. Além disso, leciono disciplinas coerentes com minha área de pesquisa e a prática na sala de aula tem sido importante espaço de reflexão, suprindo de certo modo a escassez de tempo. (Questionário 25)

Gosto pela docência e bom relacionamento com alunos. Satisfação por ter formado bons profissionais, que hoje replicam a formação construída formando bem as novas gerações de docentes e pesquisadores. Reconhecimento dos colegas, com os quais mantenho, em geral, excelente relacionamento. (Questionário 10)

Essas atividades são prazerosas por serem dotadas de uma dimensão intelectual que permite a mobilização de uma inteligência criadora e inventiva frente aos desafios do trabalho, de uma relevância social e de um reconhecimento importante para a construção de uma boa imagem de si. Tais dimensões presentes, tanto no trabalho docente quanto em outros grupos profissionais, colaboram para descarga da energia pulsional no trabalho - inscrevendo nele sua dimensão fantasmática e desejante -, assim como proporcionam melhores condições de se conquistar um prazer legítimo e construir um sentido autêntico no trabalho (Dejours, 2011a, 2011b; Mancebo, 2007; Silva, 2015). O sentimento positivo com as referidas atividades foi também identificado em pesquisa realizada com docentes de uma universidade estadual de Minas Gerais (Ruza, Silva, \& Pádua, 2013). No entanto, nem tudo é só prazer no ensino, na pesquisa-produção acadêmica e na orientação, pois a racionalidade produtivista presente na universidade, capitaneada pelo modelo de avaliação heterônomo, tem contribuído para limitar, ainda que parcialmente, a dimensão criativa e a liberdade na realização dessas tarefas (Mancebo, 2007; Silva, 2013) e a favorecer práticas cuja quantidade de produtos se sobrepõe à qualidade deles (Bosi, 2007; Dejours, 2008; Sguissardi, 2010; Sguissardi \& Silva, 2009). Dejours (2008) sintetiza estas consequências deletérias presente no atual modelo de avaliação do trabalho científico:

A avaliação da atividade científica está longe de ser satisfatória. Por um lado, ela apenas avalia os resultados da pesquisa, não o trabalho, os fracassos, o sofrimento e mobilização subjetiva e a tenacidade que ela própria implica. Por outro lado, pelos critérios de avaliação, a ciência gera efeitos perversos. A corrida desenfreada por publicações e comunicações científicas, e principalmente a multiplicação de revistas, suportes especializados e colóquios, beira o absurdo. A avaliação é acompanhada de uma constante incitação à valorização da pesquisa. Pesquisadores se esgotam para reproduzir em uma quantidade 
desmedida publicações sobre o mesmo tema, o que no fim das contas prejudica o próprio trabalho de pesquisa. (p. 88)

Frente a tudo isso, acreditamos que o sentido social do trabalho do professor pode, às vezes, ser colocado em "suspenso". Ademais, como vimos, mesmo o discurso que enfatiza a satisfação profissional pode vir a mencionar o estresse ("apesar do estresse") ou pressões temporais ("reflexão, suprindo de certo modo a escassez de tempo"), evidenciando que o prazer, gerado nesses fazeres, é, ao mesmo tempo, indissociado e irredutível do/ao sofrimento.

Todavia, as outras atividades do magistério superior, de acordo com dados do questionário, não expressam semelhante caráter de satisfação (e, portanto, de potencial prazer em sua realização). A extensão, ainda que integre o grupo de atividades intelectuais, criativas, de significativa relevância social e possa ser fonte de parceria entre a comunidade e a universidade, não se destacou nas respostas dos docentes como fator de satisfação profissional. O que se evidenciou foi um envolvimento relativamente baixo dos professores com a extensão: 30,6\% a desenvolvem. Realidade também encontrada na pesquisa feita com os docentes da universidade estadual mineira (Ruza, Silva, \& Pádua, 2013).

Já a realização de atividades administrativas, burocráticas e de representação colegiada foi frequentemente relatada como fator de insatisfação e/ou de sobrecarga de trabalho:

Cada vez há uma demanda maior para participar de discussões, atividades, criando uma fragmentação do trabalho e um ritmo intensificado. (Questionário12)

Como faço parte de um departamento com número reduzido de docentes, as inúmeras atividades ligadas à gestão acabam sendo pouco divididas, resultando em acréscimo às muitas tarefas, a docência, orientação e pesquisa. (Questionário 10)

Burocracia que, às vezes, predomina em detrimento das atividades de pesquisa e ensino. (Questionário 21)

Quando desejei trabalhar na universidade pública, desconhecia o trabalho burocrático/administrativo como tarefa docente. Isso muito me surpreendeu e até hoje sinto descontentamento sempre que tenho que trocar horas de leitura proveitosa por preenchimento maçante, repetitivo e muitas vezes improdutivo de formulários. (Questionário 25)

Tais atividades são criticadas pelos professores ao contribuírem para um acúmulo de trabalho e dificultarem a dedicação integral às atividades criativas e intelectuais, como a pesquisa, a produção acadêmico-científica, a orientação e o ensino, nas quais o professor supostamente sente maior prazer e sentido.

$\mathrm{Na}$ instituição mineira, de forma relativamente distinta, o fazer administrativo e a participação em comissões foram apontadas como trabalhosas, mas, apesar disso, os docentes consideram esse trabalho importante e apresentam certa predisposição em cooperar nesse fazer, especialmente porque a instituição requer a constante construção de espaços de funcionamento (Comitê de Ética, Centro de Pesquisa, Centro de Extensão) e de reivindicação por melhorias nas condições de trabalho. O trabalho administrativo e reivindicativo se desenhou nessa universidade como uma possibilidade para os professores fazerem rearranjos na organização de trabalho e, para alguns, tornou-se fonte mobilizadora de sentido (Ruza, Silva, \& Pádua, 2013, 2015). Por sua vez, na UNESP, certamente existe a possibilidade de alguns docentes considerarem a participação em comissões e o trabalho administrativo como espaços importantes para agir politicamente na reordenação das diretrizes de funcionamento da universidade. No entanto, tais nuanças não puderam ser constatadas na pesquisa. A frase "preenchimento maçante, repetitivo e muitas vezes improdutivo de formulários" nos parece emblemática da insatisfação e desgaste frente às exigências instrumentais de rotinização das tarefas.

$\mathrm{O}$ atual panorama da universidade tem levado a um acúmulo de trabalho, como dito, pela racionalidade gerencial realizar um descompasso entre o crescimento do número de alunos e o de professores e funcionários; e pela adoção de instrumentos de avaliação heterônomos e dotados de orientação produtivista. Frente a isso, a elevada carga de trabalho, no caso UNESP, é sentida pelo corpo docente, pois nada menos do que $72,2 \%$ consideraram seu trabalho intensificado; $13,7 \%$ parcialmente intensificado; e $11,1 \%$ não o consideraram intensificado. O que se pode depreender desses números, e que se reafirma em outros itens do questionário, é que o professor é induzido a elevar o ritmo de suas atividades (por vezes comprometendo a intenção de fazê-lo da forma como gostaria) e a estender a rotina de trabalho.

Assim, pode-se inferir que essas múltiplas demandas e exigências sejam nefastas à qualidade do trabalho produzido na universidade, ainda que o termo qualidade seja um tanto polissêmico e polêmico. O que queremos destacar, porém, é algo mais concreto e rotineiro: o docente tende a se enxergar como sobrecarregado, com salas de aula repletas de alunos, pressionado por produzir artigos e com excesso de funções a serem desenvolvidas:

À mercê de excesso de cobrança e demonstração/satisfação de atividade (relatórios e outros instrumentos de mensuração reduzidos ao lattes. (Questionário 13)

A diversidade de frentes da Universidade cobra que o professor atue nelas, e isto está dificultando a concentração na pesquisa. (Questionário 24) 
A UNESP tem priorizado o modelo quantitativo de avaliação docente e estabelece metas altas, com pressão clara pela produtividade. (Questionário 35)

Há uma cobrança cada vez maior de produção acadêmica, o que nos leva a uma intensificação do trabalho. (Questionário 36) A cobrança da produção científica mais os deveres em ensino (aulas), orientações, bancas, comissões etc., torna nosso cotidiano estafante. (Questionário 18)

$\mathrm{O}$ excesso de demandas relativas às atividades-meio compromete minhas condições de desenvolvimento de atividades-fim: docência e pesquisa. Há uma constante sensação de que estou atrasado em relação a prazos (cada vez mais curtos) e de que não tenho tempo para desenvolver pesquisa com grau de qualidade que almejo (que exige, sobretudo, tempo de amadurecimento e reflexão). (Questionário 12)

A própria natureza multiforme do trabalho docente colabora para o acúmulo de trabalho (Borsoi \& Pereira, 2013). Porém, igualmente importante para esse aumento, está a assunção de ferramentas gerenciais (discursivas e avaliativas) que procuram cooptar o docente a aceitar e naturalizar uma suposta excelência acadêmica nas múltiplas atividades do magistério superior, em especial na pesquisa-produção acadêmica (Mancebo, 2007; Silva, 2013, 2015). O professor tende a ser cooptado por esse ideal, ainda que não seja motivado exclusivamente pelo prestígio e por progressões na carreira de pesquisador, e se vê em meio a uma teia de dominação que pode levá-lo a intensificar sua dedicação ao trabalho. A rotina de trabalho vem a se estender em razão inversa ao tempo disponível para o lazer e o convívio social, afetando, em alguns casos, a dimensão familiar e social do professor, como dão mostras os seguintes dizeres:

Tenho trabalhado de manhã, à tarde e à noite, todos os dias, incluindo fins de semana e feriados. (Questionário 23)

Desde que comecei a trabalhar na UNESP, minhas férias foram dedicadas ao cumprimento de tarefas atrasadas; o tempo de descanso e entretenimento foi reduzido ao mínimo. (Questionário 25)

Sim, muito. Como eu disse acima, nunca trabalhei tanto. Por outro lado, sinto-me viva e adoro, pois é o que sempre quis da minha vida. No início, então muito mais. Mas, depois desses míseros 3 anos começo a cansar e a ver que o idealismo sucumbe perante a burocracia e vejo o quanto muitos atrapalham por não trabalharem. Tenho neste momento tentado diminuir algumas atividades para poder respirar e não desenvolver doenças emocionais, já manifestadas. Mais, para voltar a ter vida pessoal, pois muito tenho deixado de lado em minha vida pessoal e familiar por conta do trabalho sempre colocado como prioridade em minha vida e, isso, por muitas vezes, acordar, depois de 16 horas de trabalho realizado no dia anterior, com a sensação de não ter feito nada e de estar sempre devendo tudo, atrasada e sem dar conta do mínimo. (Questionário 4)

O limite entre o prazer e o sofrimento no trabalho é tênue, pois a responsabilização e dedicação em demasia, ainda que voltadas à realização de atividades potencialmente prazerosas, como o ensino, a orientação e a pesquisa-produção acadêmica, têm gerado problemas ao professor, tais como: redução do tempo de lazer; dificuldade para dedicar-se a contento a determinados fazeres; estafa, desequilíbrio psíquico-emocionais; e fragilização de vínculos afetivos, como alguns dos relatos acima deram mostras. A paixão pelo trabalho, pensando-a não apenas em sua acepção prazerosa, mas especialmente quando combinada ao processo de cooptação organizacional, tem levado o docente a procurarno trabalho uma satisfação narcísica e agressiva (reconhecimento e prestígio) que, na prática, pode se traduzir como um fetiche do prazer (Gaulejac, 2007; Silva, 2013). Em meio a isso, o docente seduzido por vezes acredita desenvolver estratégias que permitem potencializar seu prazer no trabalho, mas, como seus projetos e desejos encontram-se "fundidos" ao ideal organizacional, ele não possui a consciência de que pode estar colaborando para práticas que retroalimentam seu sofrimento, por exemplo, ritmo elevado de trabalho, fragilização das relações afetivo-familiares, esgarçamento do coletivo de trabalho, estresse desmensurado etc.

Cremos que esse processo de sedução recai invariavelmente sobre todos. Mas a adesão não é homogênea e se dá em formas e graus distintos. Mas sempre há a possibilidade de o professor estranhar e romper, ainda que não plenamente, com esses valores produtivistas. Tal possibilidade existe devido à distância entre a dimensõe prescrita e real do trabalho (Dejours, 2011a, 2011b). Assim sendo, a possibilidade de conscientização e da busca em atingir um sentido autêntico no trabalho existe, ainda que nunca ocorra ausente de contradições, conflitos e possíveis engodos.

A sobrecarga não é o único elemento nocivo para o bem-estar docente, mas as próprias relações interpessoais na universidade tendem a favorecer ou não a conquista de um equilíbrio psíquico-emocional. Na UNESP, os docentes apontam para certa heterogeneidade de percepções a respeito do ambiente de trabalho. A maioria o considera bom (61,1\%), porém poucos não têm objeções ao ambiente de trabalho, considerando-o ótimo (19,4\%), e 16,7\% o considera regular, deixando mais evidente certo descontentamento. Por fim, $2,8 \%$ não opinou. São múltiplos e, por vezes, conflitantes os motivos para a satisfação ou insatisfação com o ambiente de trabalho, pois, enquanto alguns dizem ter um ambiente agradável de trabalho e sentirem-se reconhecidos; outros fazem alusão a conflitos, competições e a existência de uma politização e ideologização do ambiente de trabalho. Esta multiplicidade de posicionamentos é vista nos seguintes dizeres: 
Ambiente agradável, relação com companheiros e reconhecimento profissional. (Questionário 28)

A amizade dos colegas de trabalho (Questionário 20); Convívio com colegas/amigos. (Questionário 24)

Considero que meu trabalho é excelente, estabelecendo parcerias com colegas, alunos e técnicos administrativos. (Questionário

3)

Desenvolvo atividades que me dão imensa satisfação: pesquisa, orientação de alunos, docência, despertar interesse dos alunos pelo conhecimento, bom relacionamento com alunos interessados em aprender e com meus orientandos. (Questionário 19)

Excesso de politização e ideologização do ambiente de trabalho (Questionário 6);

Competição; Conflitos. (Questionário 11)

Muito jogo político nas relações interpessoais e administrativas; falta de diálogo verdadeiro; dificuldade em se ver projetado nas organizações institucionais. (Questionário 34)

Ter um bom relacionamento no trabalho é condição importante para a busca de prazer sublimatório, para se evitar o sofrimento e transformá-lo, pela mediação do reconhecimento. Isto ocorre porque o reconhecimento dos atores é condição imprescindível para a validação de uma descoberta exitosa de si, pois ele atua não só na satisfação narcísica, mas a supera, ao permitir ao profissional desenvolver um sentido autêntico no trabalho. Permite, ainda, o funcionamento da dinâmica cooperação-retribuição que propicia maiores condições para os atores agirem criativamente e politicamente na procura por rearranjar aspectos nocivos presentes nas normas e no próprio coletivo de trabalho (Dejours, 2011a, 2011b). No entanto, toda uma literatura (Bosi, 2007; Mancebo, 2007; Sguissardi \& Silva, 2009; Silva, 2013, 2015) composta por pesquisadores dedicados a analisar a educação superior brasileira - como já abordado - aponta que a universidade brasileira tem sido alvo de profundas transformações produtivas, bem ao espírito gerencial, no sentido de otimizar seu funcionamento e propagar junto ao docente uma aceitação e naturalização da cultura da excelência e de seus pressupostos produtivistas. O professor, então, se vê interpelado por elevada carga de trabalho, trabalhando e cooperando, por vezes, de forma deliberada ou inconsciente para um ambiente demasiado competitivo e individualista.

A hipótese construída para entender o caso em questão da pós-graduação da UNESP é que a dinâmica de cooperação e reconhecimento entre os pares não está necessariamente impedida, mas fragilizada por se reduzir a pequenos grupos unidos por afinidades. Se, por um lado, o fator relacional está fragilizado entre os docentes, por outro, percebe-se que eles estabelecem boas relações com os discentes e apontam sentir seus trabalhos reconhecidos por eles.

O modelo em voga de universidade pública tem contribuído para que o professor universitário vivencie uma série de contradições entre as exigências institucionais e sua subjetividade. O professor, em meio a isso, por vezes recai em sofrimento e adoecimento, ainda que vivências de prazer e de realização profissional também o acompanhem. O adoecimento no trabalho, como já expresso em alguns dizeres, se apresenta evidente nos programas de pós-graduação analisados, ainda que possa também estar relacionado à disposições pessoais e problemas de ordem diversa. Todavia, merece destaque o elevado percentual no grupo analisado: 77,8\% respondeu já ter adoecido por conta de algo relacionado ao trabalho, acompanhado de $22,2 \%$ que atribui nunca ter adoecido. Dentre os $77,8 \%$ que atribuem ter adoecido em alguma medida por conta de algo relacionado ao trabalho, $11,1 \%$ diz ter ocorrido muitas vezes, $27,8 \%$ algumas vezes, $11,1 \%$ poucas vezes e $27,8 \%$ raramente.

As crises e sofrimentos laborais podem culminar em adoecimento. Mas tal nem sempre ocorre. Sofrimentos recorrentes muitas vezes não se traduzem em doenças que requerem medicação e afastamentos do emprego, mas se fazem presentes numa série de sintomas nocivos ao bem-estar do professor que foram ressaltados pelo corpo docente, a saber: estresse (72,2\%); fadiga (66,7\%); ansiedade (50\%); alteração repentina do estado de humor (41,7\%); insônia ou dificuldade de dormir (38,9\%); estado depressivo passageiro (38,9\%); dificuldade de concentração e memória (30,6\%); problemas na voz $(30,6 \%)$; dores musculares (30,6\%); e problemas cardíacos (11,1\%). Ademais, ressalta-se, ainda, escores significativos de sensações que os docentes destacaram ser nocivas no trabalho: sensação de sobrecarga (83,3\%); sensação de não conseguir cumprir com as atividades (50\%) e de desmotivação profissional (25\%).

Tais percentagens de adoecimentos e de sintomas e sensações nocivas ao bem-estar do professor evidenciam que, além de expressivos, envolvem intrincados processos somático-psíquicos, ou ainda, relações entre subjetividades forjadas e formas históricas de sociabilidade pragmática e produtiva. Compreendemos ser esse mal-estar docente, que envolve desde adoecimentos até multiformes sofrimentos que se expressam em distintos sintomas somáticos e/ou psíquicos, decorrente da contradição entre a subjetividade do professor e a realidade do trabalho, configurada por múltiplas exigências institucionais: metas de produtividade nos indicadores de desempenho; necessidade de atingir elevada produtividade acadêmica; competitividade, individualização e conflitos entre o corpo de docente; e multiplicidade de atividades do magistério superior a serem desenvolvidas concomitantemente. Fatores já apontados pela literatura (Borsoi \& Pereira, 2013; Bosi, 2007; Mancebo, 2007; Sguissardi \& Silva, 2009; Silva, 2013, 2015) como causadoras de adoecimento e sofrimento ao professor de outras universidades. 
Em síntese, os dados da pesquisa apontam que os professores da pós-graduação da UNESP, no geral, apresentam sentimentos e relatos positivos acerca de seu trabalho, ainda que não sejam plenos nem tampouco para todo o coletivo. Participam disto aspectos como a identificação e a dimensão criativa e potencialmente prazerosa inscrita nas atividades de construção e transmissão do conhecimento, assim como o reconhecimento dos atores da universidade. Não obstante, a análise mais aprofundada do conjunto das respostas nos indica que o reconhecimento se apresenta, por vezes, minimamente fragilizado. Tal aspecto se evidencia melhor no caso dos professores que apontam para existência de conflitos, competição e interesses políticos de pequenos grupos presentes nas relações sociais e de poder na instituição universitária.

Destacamos que o poder gerencial atua na universidade com o objetivo de racionalizar os recursos humanos. Difundese e incute-se nos professores e técnicos administrativos a cultura da excelência e do produtivismo acadêmico. Tal feito, aliado à sobrecarga de trabalho decorrente das múltiplas atividades do magistério superior, especialmente com a realização de atividades administrativas e burocráticas, tem contribuído para limitar parcialmente as dimensões potencialmente prazerosas e geradoras de sentido do trabalho docente, além de ocasionar sofrimento e, em alguns casos, adoecimento. Por fim, no interior de uma série de contradições, verificamos que o sofrimento se faz presente no trabalho docente, ainda que não somente em sua forma patogênica. O sofrimento estabelece com o prazer múltiplas relações dialéticas e, por vezes, contraditórias, relacionadas tanto às disposições pessoais de cada professor como ao modelo quantofrênico de avaliação do trabalho. O prazer, portanto, tal como o sofrimento, do qual é indissociado, apresenta distintas expressões.

\section{Considerações Finais}

Conclui-se que a subjetividade do professor da pós-graduação da UNESP não se constrói como uma realidade autônoma, mas se inscreve em determinado contexto político-econômico, configurado pela predominância da esfera financeira de acumulação capitalista (mundialização do capital) e pela conformação da reforma do aparelho de Estado e das políticas educacionais às diretrizes neoliberais. Nessa configuração, efetuaram-se profundas reformas no papel a ser desenvolvido pela universidade, transformando-a em uma instituição gerencial, competitiva, produtivista e mercantilizada.

Bem ao espírito neoliberal, o modelo de gestão gerencial realiza uma política de racionalização de recursos humanos e financeiros na universidade. No entanto, ao desconsiderar as especificidades desta instituição e do trabalho docente, tal feito contribui para a elevação de uma suposta "eficiência" e "eficácia" que, na realidade, se traduz em precarização institucional e prejuízos ao bem-estar docente e ao trabalho desenvolvido na universidade. Gestores e formuladores de políticas públicas educacionais protagonizam, não sem conflitos, a difusão e naturalização da cultura da excelência ou high performance que se traduz numa doença da medida ou quantofrenia, forjando uma situação na qual tudo precisa ser matematicamente traduzido, o que implica formas de controle e manipulação da subjetividade. O professor da UNESP, que atua na universidade produtivamente reformada, vive uma relação conflituosa entre as exigências institucionais da universidade e sua subjetividade. Como apontávamos, sofrimento e prazer se articulam em múltiplas relações dialéticas e contraditórias. O sofrimento patogênico, por vezes falseado por um suposto prazer efetivo, se faz presente nas seguintes situações: nas dominações organizacionais, especialmente pela via da malversação da dinâmica do reconhecimento; no sistema heterônomo de avaliação da pós-graduação e do trabalho docente; na elevada competitividade nas relações de trabalho; nas demandas multiformes de trabalho; na sobrecarga profissional, entre outros. Por sua vez, o prazer sublimatório, ainda que não destituído de certo grau de sofrimento e, em algumas situações, sustentado por um sofrimento criativo, seria propiciado: pelas atividades de pesquisa, produção acadêmica, ensino e orientação; por relações de afinidades desenvolvidas com os pares, alunos e funcionários na universidade; por átimos de uma dinâmica do reconhecimento que, por vezes, se contrapõe à sua malversação; pela relevância social do trabalho docente, entre outros.

Portanto, concluímos que, nesse jogo intrincado do par antitético prazer-sofrimento, ficam abertas várias possibilidades para as subjetividades docentes, que se situam entre o sofrimento patogênico e o sofrimento criativo. E se podemos indicar existir múltiplas relações entre sofrimento e prazer, a análise dos dados da universidade pesquisada e do questionário evidenciam: intensificação do trabalho; desgaste frente às exigências de rotinização das tarefas; e significativo número de referências ao estresse e/ou adoecimento. Porém, tais aspectos não possibilitam apontar para uma suspensão do prazer, ou, mais precisamente, para uma suspensão de caráter contínuo ou ininterrupto. Não obstante esta ressalva, o que nos parece predominar são as formas forjadas de prazer agressivo e fetichizado, geralmente acompanhadas do sofrimento patogênico e de uma tendência de malversação das dinâmicas de reconhecimento. Tal predominância, porém, não elimina alternativas. Assim, consideramos que as formas predominantes de prazer-fetiche/sofrimento patogênico são, estas sim, eventualmente suspensas. E ainda que o sejam em átimos do cotidiano institucional, ensejam formas micropolíticas de prazer sublimatórias que, acompanhadas por sofrimento criativo, tencionam as tendências predominantes que lhes são contrárias. 


\section{Referências}

Aubert, N., \& Gaulejac, V. (1991). Le coût de l'excellence. Paris: Editions du Seuil.

Borsoi, I. C.F., \& Pereira, F. S. (2013). Professores do ensino público superior: Produtividade, produtivismo e adoecimento. Universitas Psycholgica, 12(4), 1211-1233. http://doi.org/10.11144/Javeriana.UPSY12-4.peps

Bosi, A.P. (2007). A precarização do trabalho docente nas instituições de ensino superior do Brasil nesses últimos 25 anos. Educação \& Sociedade, 28(101), 1503-1523.

Bourdieu, P. (2004). Os usos sociais da ciência:Por uma sociologia clínica do campo científico. São Paulo: Editora UNESP.

Cardoso, F. H. (2007). Reforma do Estado. In L. C. Bresser-Pereira, \& P. K. Spink(Orgs.), Reforma do Estado e administração pública gerencial (7a ed., pp.15-20). São Paulo: FGV.

Chesnais, F. (1996). A mundialização do capital. São Paulo: Xamã.

Dejours, C. (2008). Avaliação do trabalho submetida à prova do real: Crítica aos fundamentos da avaliação. In L. I. Sznerlwar \& F. L. Mascia (Orgs.), Cadernos de TTO (nº 2). São Paulo: Editora Blucher.

Dejours, C. (2011a). Da psicopatologia à psicodinâmica do trabalho. In S. Lancman \& L. I. Sznelwar (Orgs.), Christophe Dejours: Da psicopatologia à psicodinâmica do trabalho (3a ed., pp. 57-124). Rio de Janeiro: Editora Fiocruz.

Dejours, C. (2011b). Entre sofrimento e reapropriação: O sentido do trabalho. In S. Lancman \& L. I. Sznelwar (Orgs.), Christophe Dejours: Da psicopatologia à psicodinâmica do trabalho (3 ${ }^{\mathrm{a}}$ ed., pp. 433-448). Rio de Janeiro: Editora Fiocruz.

Freud, S. (1996). Além do princípio do prazer. In J. Strachley (Ed.), Edição Standard Brasileira das Obras Completas de Sigmund Freud (pp. 12-85). Rio de Janeiro: Imago. (Originalmente publicado em 1920)

Gaulejac, V. (2007). Gestão como doença social: Ideologia, poder gerencialista e fragmentação social. Aparecida, SP: Ideias \& Letras.

Mancebo, D. (2007). Trabalho docente: Subjetividade, sobreimplicação e prazer. Psicologia: Reflexão e Crítica, 20(1), 7480.

Martinez, M. C., \& Paraguay, A. I. B. B. (2003). Satisfação e saúde no trabalho: Aspectos conceituais e metodológicos. Cadernos de Psicologia Social do Trabalho, 6, 59-78.

Merlo, Á., \& Mendes, A. (2009). Perspectivas do uso da psicodinâmica do trabalho no Brasil: Teoria, pesquisa e ação. Cadernos de Psicologia Social do Trabalho, 12(2), 141-156.

Paulani, L. (2008). O projeto neoliberal para a sociedade brasileira: Sua dinâmica e seus impasses. In L. Paulani (Eds.), Brasil delivery (pp. 105-139). São Paulo: Boitempo.

Ruza, F.M., Silva S. M., \& Pádua, K. C. (2013). A identidade no e pelo trabalho: Elementos constituintes da identidade profissional dos professores da FaE/CBH/UEMG. Perspectiva (UFSC), 31(3), 1099-1129.

Ruza, F.M., Silva S. M., \& Pádua, K. C. (2015). Ser professor universitário: Identidades construídas entre aspectos de satisfação e insatisfação profissional. Linhas Críticas, 21(44), 179-199.

Sguissardi, V. (2010). Produtivismo acadêmico. In D. A. Oliveira, A. M. C. Duarte, \& L. M. F. Vieira (Eds.), Dicionário: Trabalho, profissão e condição docente. Belo Horizonte: UFMG/Faculdade de Educação. 
Sguissardi, V., \& Silva Júnior, J. R. (2009). Trabalho intensificado nas federais: Pós-graduação e produtivismo acadêmico. São Paulo: Xamã.

Silva, E. P. (2013). Sofrimento psíquico no trabalho do professor da universidade pública. In L. G. Freitas (Org.), Prazer e sofrimento no trabalho docente (pp. 71-92). Curitiba: Juruá.

Silva, E. P. (2015). Adoecimento e sofrimento de professores universitários: Dimensões afetivas e ético-políticas. Revista de Psicologia: Teoria e Prática, 17(1), 61-71.

Universidade Estadual Paulista. (2004). Anuário Estatístico - 2003. São Paulo. Recuperado de http://www.unesp.br/ape/ mostra_arq_multi.php?arquivo $=4738$

Universidade Estadual Paulista. (2007). Instrução Normativa 01/2007 - CPA. Critérios de Desempenho Docente. São Paulo. Recuperado de http://www.franca.unesp.br/Home/asdfa/instrucao_normativa_01_07.pdf

Universidade Estadual Paulista. (2014). Anuário Estatístico - 2013. São Paulo. Recuperado de https://ape.unesp.br/anuario/ pdf/Anuario_2014.pdf

\section{Endereço para correspondência}

Fábio Machado Ruza

End.: Rua José de Alencar, 71, ap. 32, Vila Costa do Sol - São Carlos - SP - Brasil. CEP: 13566-000.

E-mail: fabioruza@yahoo.com.br

Eduardo Pinto e Silva

End.: Universidade Federal de São Carlos (UFSCar), Departamento de Educação, Rodovia Washington Luiz, km 234, Monjolinho - São Carlos - SP - Brasil. CEP: 13565-905.

E-mail: dups@ig.com.br 